\title{
THE USE OF SOCIAL MEDIA IN B2B MARKETING AND BRANDING: AN EXPLORATORY STUDY ${ }^{1}$
}

\author{
Ross Brennan (author for correspondence) \\ Hertfordshire Business School \\ University of Hertfordshire \\ College Lane \\ Hatfield \\ Hertfordshire \\ AL10 9AB \\ d.r.brennan@herts.ac.uk \\ Tel. +44 (0) 7905916457 \\ Fax. +44 (0) 1707284115 \\ Robin Croft \\ University of Bedfordshire \\ Park Square \\ Luton \\ Bedfordshire \\ LU1 3JU
}

Ross Brennan is a Reader in Marketing at the University of Hertfordshire. His primary area of research interest is business-to-business marketing. Ross has been associated with the work of the IMP (Industrial Marketing \& Purchasing) Group for many years. In addition, Ross has coauthored a number of textbooks, notably Business to Business Marketing (Sage) with Louise Canning and Raymond McDowell, and Marketing: An Introduction (European Edition) (Pearson) with Gary Armstrong, Philip Kotler and Michael Harker. Formerly, Ross was a Reader in Marketing at Middlesex University and, prior to that, spent 11 years in marketing and strategic management positions at British Telecommunications plc.

Robin Croft is a Reader in Marketing at the University of Bedfordshire. He has held positions at 3 other UK universities since the early 1990s, and is the author of over 70 journal articles, book chapters and conference papers. He is a graduate of the universities of Oxford and Salford. He started his career in manufacturing, working in B2B roles in the packaging industry before moving into market research and consultancy. Since 2006 he has become immersed in the new technologies of social media and Web 2.0, which is where the bulk of his teaching and writing has now moved. He has appeared on TV, radio and in the press many times talking about new media and other related themes.

${ }^{1}$ This is a preprint (pre peer-review) version of a paper submitted for consideration for the Journal of Customer Behaviour, (C) Westburn Publishers Ltd, http://www.westburn.co.uk 


\title{
THE USE OF SOCIAL MEDIA IN B2B MARKETING AND BRANDING: AN EXPLORATORY STUDY
}

\begin{abstract}
While the tools of social media are ubiquitous in contemporary consumer marketing, there is little evidence about the extent to which they have been adopted by business-to-business marketers. Although experts argue that B2B firms can and should use platforms such as FaceBook and YouTube, almost all of the popular examples used in mainstream seminars, conferences and the practitioner press are of consumer brands. Our exploratory study used content analysis and text-mining to look at current B2B marketing practitioner literature on the subject, and examined ten large B2B technology companies to profile their use of social media. We found that although large companies were extensive users of almost all the mainstream social media channels, the adoption of these tools was by no means universal. It seems that USbased firms are the furthest ahead in using social media for B2B marketing. The B2B social media pioneers are striving to use these tools to position themselves as 'thought leaders', to take a market-driving role in the sector and to build relationships with a range of stakeholder groups.
\end{abstract}

\section{Keywords}

Social media, FaceBook, LinkedIn, blogging, podcasts, thought leadership 


\section{INTRODUCTION}

Business-to-business marketers have been using Internet applications widely for several years now (Leek, Turnbull \& Naude 2003), and there is an extensive body of knowledge around the use of web-based branding in the sector. However, the web has moved on: what was largely didactic, one-way computer-mediated communication has now changed with the evolution of social media platforms and what have been termed Web 2.0 applications. Constantinides and Fountain (2008: 231) defined Web 2.0 as "a collection of open-source, interactive and usercontrolled online applications expanding the experiences, knowledge and market power of the users as participants in business and social processes... [supporting] the creation of informal users' networks facilitating the flow of ideas and knowledge by allowing the efficient generation, dissemination, sharing and editing/refining of informational content." At the time of writing the most successful example of this type of thinking is the social networking site FaceBook, a media phenomenon that is widely discussed in terms of the speed of its adoption and the sheer breadth of its reach. Marketers of consumer goods and services, particularly of products targeted at younger age groups, have had no option but to develop social media marketing strategies, because their target audience spends a great deal of time online, interacting with friends and family through such media. Consequently, consumer marketing is now a highly visible part of what is being described as the social media revolution - examples abound, but the Coca Cola FaceBook presence is a highly regarded example (www.facebook.com/cocacola). Where once a company of this importance would have directed audiences from conventional advertising channels towards corporate web pages, it now highlights the FaceBook URL instead, recognizing perhaps that this is the space inhabited by its most attractive target markets. Business-to-business marketers have to decide whether, and how, to employ such media, both those purpose-built for business professionals (such as LinkedIn) and more generic media (such as FaceBook and Twitter), in their branding strategies.

In this exploratory study we focused on the technology sector for evidence of how business-tobusiness companies have engaged with social media. We narrowed our focus to firms operating in the information technology sector only. There were some sound reasons for doing this: firstly it meant we were comparing organizations all working in the same dynamic business environment; secondly because technology companies such as Oracle and Cisco have themselves spearheaded new Web 2.0 business models (see for example Tapscott and Williams 2006), as well as enabling the whole social media phenomenon to develop through incremental improvements in connectivity; and thirdly because of the widely-shared belief in this huge sector that social media are of relevance only to consumer brands. This latter point is made plainly in the lists of case studies and industry speakers in almost all industry conferences on social media. Similarly, while Agresta and Bough's authoritative work on social media marketing (2011: 5861) makes the point that $\mathrm{B} 2 \mathrm{~B}$ companies can and do use social media tools, their focus is almost 
entirely on B2C. Related points had made by Weber (2007), who drew on examples including Oracle, Microsoft, Hewlett-Packard and Dell.

\section{THE STUDY}

The empirical component of the study comprised two phases, an analysis of professional papers concerning B2B digital marketing, and a semi-structured content analysis of social media material disseminated by 10 large B2B businesses operating in the high-technology sector.

In the first phase, in order to explore the issues in B2B social media marketing that are of current concern to marketing practitioners, 20 recent professional articles on this topic were subjected to formal content analysis. The articles were sourced from five websites which aim to act as digital marketing knowledge hubs for marketing practitioners:

www.b2bm.biz - a dedicated B2B digital marketing website; www.baseone.co.uk - a specialist B2B digital marketing agency; WwW.mointernational.com - a specialist B2B digital marketing agency; www.mycustomer.com - a dedicated CRM and digital marketing website; http://searchenginewatch.com - a dedicated digital marketing website.

The 20 articles were purposefully selected by the authors to represent recent contributions by B2B digital marketing practitioners concerning the use of social media for B2B marketing purposes. The authors of these articles all work in digital media agencies, and the articles are clearly intended not simply to convey useful information, but also to promote the author and his/her agency to prospective clients. Nevertheless, these articles were chosen because they are substantial pieces of work (average length 1,543 words) which can be sharply distinguished from simple blog posts, since they demonstrate considerable reflection and often refer to commercial market research reports. The following are illustrative of the titles of articles included in the analysis:

"Survey of B2B buyers' use of social media"

"5 top tips when using FaceBook for B2B businesses"

"How will LinkedIn's company pages impact social media marketing?"

"Open doors with B2B social networking"

"How to plan a social media strategy."

In the second phase, we examined 10 business-to-business companies which between them employ around half a million people worldwide. Global technology firms that address both B2C and B2B markets (for example industry giants such as IBM, Microsoft, Dell and Hewlett Packard) were not included. Instead we chose large organizations that concentrate exclusively, 
or principally, on the $\mathrm{B} 2 \mathrm{~B}$ sector. As elsewhere in this study we used the tools of social media themselves to refine the choice, adding a virtual Delphi approach to the initial scoping of study: we used one of the technology forums on business networking site LinkedIn to generate and test ideas. Initially this guided us towards studying 3-4 discrete sectors (enterprise software, data networking, data storage and semiconductors); in the event diverse companies such as Oracle were difficult to categorize, so our eventual sample avoided these sectoral definitions and tended to focus firstly on systems and secondly on microprocessors. This hardware-software dichotomy was mirrored in other choices made: while half of the sample consisted of US firms, European and Asian companies made up the rest. They ranged in size from Oracle with over 100,000 employees down to Qualcomm with 16,000 staff (see Table 1). 
Table 1: companies used in this study

\begin{tabular}{|l|l|l|l|}
\hline Name & $\begin{array}{l}\text { Nature of } \\
\text { business }\end{array}$ & Employees & Origin \\
\hline Oracle & $\begin{array}{l}\text { Enterprise } \\
\text { software }\end{array}$ & 105,000 & USA \\
\hline Intel & Semiconductors & 83,500 & USA \\
\hline Cisco Systems & Networking & 70,700 & USA \\
\hline $\begin{array}{l}\text { STMicroelectro } \\
\text { nics }\end{array}$ & Semiconductors & 50,500 & Switzerland \\
\hline Hynix & Semiconductors & 50,000 & Korea \\
\hline SAP & $\begin{array}{l}\text { Enterprise } \\
\text { software }\end{array}$ & 47,600 & Germany \\
\hline $\begin{array}{l}\text { Renesas } \\
\text { Technology }\end{array}$ & $\begin{array}{l}\text { Semiconductors } \\
\text { Infineon }\end{array}$ & 47,000 & Japan \\
\hline Symantec & $\begin{array}{l}\text { Enterprise } \\
\text { software }\end{array}$ & 18,400 & USA \\
\hline Qualcomm & Semiconductors & 16,100 & USA \\
\hline
\end{tabular}


Methodologies for studying the social media phenomenon are still emerging and being tested by researchers. Some of the more successful approaches which evolved as the world wide web grew in importance involve adaptations of traditional ethnography; probably the best know of these include Hine's 2000 methodological guide Virtual Ethnography, as well as applied studies such as Miller \& Slater (2000). The open-ended methods of immersion, observation and content analysis are a useful starting point when studying a new phenomenon such as this, although it has to be remembered that these authors were dealing with a web prior to the existence of most of the social media that our present study set out to understand. The closest that researchers from this period came to Web 2.0 and social media were the discussion forums that had been a feature of the Internet from its inception.

This area is therefore not entirely unknown, but it is reasonable to say that it is under-researched. From the published sources detailed above, plus a parallel review of scholarly sources, we came to the view that the use of social media would inevitably become an important component of business-to-business branding strategy, particularly in high-technology industries. The reasoning behind this assertion was that social media can contribute to three important trends in businessto-business marketing: the trend for marketing to become an information handling task (Naude and Holland 2004), the trend towards relationship-based marketing (Wilson and Vlosky 1998, Ryssel, Ritter and Gemunden 2004, Piercy 2010), and the need for marketing to be market driving rather than market driven in high-technology industries (Hills and Sarin 2003, Sarin and Mohr 2008).

\section{BUSINESS-TO-BUSINESS MARKETING AND SOCIAL MEDIA}

Naude and Holland (2004) proposed that business-to-business marketing has moved from the transactional approach, through the relationship approach, and into a new era that they call information marketing. In this new era marketing, Naude and Holland claim, becomes primarily an information- handling problem; this is to assert that the successful acquisition, analysis and deployment of information is the key to marketing success in the putative new era.

Consequently, according to Naude and Holland (2004), the most successful marketing organizations in this era will be those that make the most effective use of IT tools in developing their marketing strategy. The latest IT tools to emerge, which are yet to be fully evaluated for business-to-business marketing, are social media. The following research question emerges from this discussion:

RQ1: What part can social media play in the development of an information-based approach to business-to-business branding? 
The influence of developments in IT on inter-organizational relationship management is a matter of enduring interest (Wilson \& Vlosky 1998, Ryssel, Ritter \& Gemunden 2004). Nevertheless, according to Ryssel et al (2004: 197): "the impact of IT on relationships, and their social aspects in particular, have not been discussed sufficiently". De Ruyter, Moorman and Lemmink (2001: 280) remarked that: "Relationships in high-technology markets are a complex phenomenon". They pointed out that the supplier has to contend with buyer skepticism about new technologies, and with the constant threat of obsolescence resulting from the development of newer technologies. However, in high technology markets it is common to encounter relatively high buyer switching costs and considerable buyer commitment to the technology of a specific vendor (Wilson \& Vlosky 1998). According to De Ruyter et al (2001) high-technology markets are perceived as high risk by both buyers and sellers, so that the role of trust and commitment in supplier-customer relationships is particularly important; this, in turn, makes the boundaryspanning function key. Boundary-spanners have a role to play in reducing perceived risk and uncertainty by building trust and commitment. Consequently, the active management of suppliercustomer relationships in order to ensure a continuous flow of information and to build trust and commitment are particularly important in supplier-customer relationships in high technology markets. Two important research questions follow from this discussion, namely:

RQ2: To what extent can social media play a part in actively managing business-tobusiness buyer-seller relationships?

RQ3: Can social media be used to facilitate the development of trusting relationships between buyers and sellers?

Hills and Sarin (2003), Sarin and Mohr (2008), and Mohr and Sarin (2008) have argued that in high-technology industries a strategy of market driving will be more successful than being market driven. The focus on the market orientation concept in the 1990s, notably in the work of Kohli and Jaworski (1990), suggested that marketing should generally be responsive to market developments rather than seeking to bring about change. However, Hills and Sarin (2003) contended that a responsive orientation is inappropriate in high-technology industries, where there are typically very high rewards available to a firm that can establish itself as a real or de facto industry standard. Hills and Sarin (2003) conceptualized market driving along three dimensions: value creation (an emphasis on innovative activities), change (being seen to be a change agent or change catalyst), and leadership (setting the agenda for other industry participants to follow). Active participation in business-to-business social media networks can be seen to contribute along all three of these dimensions, and therefore to be a potentially valuable component of a market driving strategy in a high-technology industry. The business-to-business marketer who successfully implements a social media marketing strategy will create value for other stakeholders and will create conditions for change within the industry by developing a new and vibrant forum for the exchange of information and the collaborative development of new technical and commercial ideas. In addition, the goal of much social media marketing - in 
particular, the use of blogs - is to position the originator as a thought leader in the field. According to Hills and Sarin (2003: 18): "The primary objective of market driving firms is to influence the evolution of their industry in a direction consistent with their own strengths and abilities, and to derive long-term advantage from such an evolution." As we will see, this aspiration is very similar to the aims that digital marketing professionals consider appropriate for a social media marketing strategy. This leads to the final research question:

RQ4: Can social media be used as a significant component of a market driving brand strategy in high-technology business-to-business markets?

\section{FINDINGS FROM ANALYSIS OF PROFESSIONAL LITERATURE}

Tables 2 and 3 present the results of two analyses conducted on the text of the 20 professional articles. These analyses were a word-frequency count (using the Wordstat module within QDA Miner) and text mining (using the TerMine service provided by the UK National Centre for Text Mining at www.nactem.ac.uk). The fundamental aim of text mining is to provide computerized tools that can analyze natural language text and extract information that has meaning for the human reader. Text mining involves the application of techniques from areas such as information retrieval, natural language processing, information exchange and data mining. That is to say that the text mining process 'makes sense' of a dataset of documents by using search routines, the computerized analysis of natural language (such as part-of-speech tagging and parsing), data structuring (such as the identification of key terms), and knowledge discovery (identifying patterns in large sets of data) (National Text Mining Centre 2008). Text mining software extracts from the textual data words and short phrases which have a high probability of being legitimate scientific terms in the domain of interest, and ranks them in order of their 'likelihood of termhood'. 
Table 2: Frequency count of selected terms in 20 B2B social media articles

\begin{tabular}{|l|l|l|l|}
\hline & Frequency & $\begin{array}{c}\text { \% } \\
\text { Shown }\end{array}$ & $\begin{array}{c}\text { \% } \\
\text { Total }\end{array}$ \\
\hline Social & 334 & $21.2 \%$ & $1.1 \%$ \\
\hline Media & 254 & $16.1 \%$ & $0.8 \%$ \\
\hline LinkedIn & 153 & $9.7 \%$ & $0.5 \%$ \\
\hline Content & 127 & $8.1 \%$ & $0.4 \%$ \\
\hline Twitter & 91 & $5.8 \%$ & $0.3 \%$ \\
\hline FaceBook & 88 & $5.6 \%$ & $0.3 \%$ \\
\hline $\begin{array}{l}\text { Blog/Blogs/Blog } \\
\text { ging }\end{array}$ & 88 & $5.6 \%$ & $0.3 \%$ \\
\hline Network/s & 56 & $3.6 \%$ & $0.2 \%$ \\
\hline Research & 53 & $3.4 \%$ & $0.2 \%$ \\
\hline Prospect/s & 50 & $3.2 \%$ & $0.2 \%$ \\
\hline Networking & 45 & $2.9 \%$ & $0.1 \%$ \\
\hline Brands & 42 & $2.7 \%$ & $0.1 \%$ \\
\hline Conversation & 39 & $2.5 \%$ & $0.2 \%$ \\
\hline Benefit/s & 39 & $2.5 \%$ & $0.2 \%$ \\
\hline Relationships & 38 & $2.4 \%$ & $0.1 \%$ \\
\hline Buyers & 31 & $2.0 \%$ & $0.1 \%$ \\
\hline Salespeople & 27 & $1.7 \%$ & $0.1 \%$ \\
\hline Fan & 22 & $1.4 \%$ & $0.1 \%$ \\
\hline
\end{tabular}

Source: Original 
For Table 2, words that are particularly relevant to social media marketing have been extracted from the overall content analysis. In Table 2, column 1 shows the word, column 2 shows the frequency with which it occurred across all 20 articles, column 3 shows the percentage of the word occurrences represented in the Table, and column 4 shows the percentage of the word occurrences from the entire 20 articles (example: the word 'social' occurs 334 times, and represents $1.1 \%$ of all the words used in the 20 articles). From Table 2 we can see that LinkedIn, Twitter, FaceBook and blogging are considered to be the key social media for B2B marketing, and that 'content marketing', market research, prospecting and networking are prominent B2B marketing applications for social media. In 'content marketing' a B2B marketer seeks to deliver interesting business-related content to customers (and possibly other stakeholders) through social media in order to become an influential hub in the social network. This reflects a general theme to be found from reading the $20 \mathrm{~B} 2 \mathrm{~B}$ social media articles, that when using social media the hard-sell approach should be avoided, and that the goal should be to develop trust in the brand with a view to generating a medium- or long-term business pay-off.

Table 3 shows the 20 top 'terms' generated by text-mining the 20 articles on B2B social media. In several respects this analysis corroborates the analysis shown in Table 1. LinkedIn, FaceBook, Twitter and blogging are all represented in the top 20 terms, as are the activities of content marketing, market research and (social) networking. Prospects and prospecting do not emerge strongly from the text mining analysis (they are to be found in the list of potential terms generated by the software, but much lower down the ranking than the terms shown in Table 2). 'Fan page', the third ranked term in Table 2, is a FaceBook-related term. Businesses, and other organizations, can create fan pages on FaceBook. Prominent business-to-business marketing businesses that have created a substantial FaceBook presence through an official fan page include Sodexo, Oracle, Intel and Cisco. 
Table 3: Top 20 social media terms extracted from 20 B2B social media articles

\begin{tabular}{|l|l|}
\hline Term & $\begin{array}{l}\text { C- } \\
\text { value }\end{array}$ \\
\hline Social networking & 30.1 \\
\hline $\begin{array}{l}\text { B2B social } \\
\text { networking }\end{array}$ & 22.8 \\
\hline Fan page & 17.5 \\
\hline $\begin{array}{l}\text { Content } \\
\text { marketing }\end{array}$ & 15.9 \\
\hline Social media & 15 \\
\hline LinkedIn group & 14 \\
\hline B2B marketing & 13.8 \\
\hline Company pages & 12 \\
\hline Market research & 10 \\
\hline Target audience & 9 \\
\hline Decision maker & 8.5 \\
\hline B2B marketer & 8 \\
\hline FaceBook page & 8 \\
\hline Brand awareness & 7 \\
\hline Blog post & 5 \\
\hline Social platform & 5 \\
\hline Supplier websites & 5 \\
\hline Direct mail & 5 \\
\hline $\begin{array}{l}\text { Online } \\
\text { community }\end{array}$ \\
\hline Twitter account & 5 \\
\hline
\end{tabular}

Note: a higher c-value indicates a higher 'likelihood of termhood' within the field. Source: Original 


\section{FINDINGS: BY PLATFORM}

Despite the misgivings of participants in the early stages (some of the B2B marketing managers involved in the virtual Delphi stage), most of the mainstream social media platforms were being used by technology companies. One major exception was the once dominant Myspace, which was unsurprising as its focus has always been consumer products (especially popular music) and youth. We found only slight interest in Google's photo sharing site Picasa, while the Yahoo! equivalent was well represented in the study. Similarly the business networking site Plaxo did not feature, whereas LinkedIn was universally present.

By far the world's largest social media platform, FaceBook was represented in all searches: this was perhaps unsurprising as the software appears automatically to create company pages for any organization which is represented significantly in the membership data. But while Intel and Cisco appeared to have high levels of engagement on FaceBook (Intel had nearly 300,000 'likes' or fans, to Cisco's 125,000), smaller companies in our sample like Renesas and Infineon's fans numbered in the hundreds. Indeed, a FaceBook group set up for ex-employees of Hynix had more members than the official company group, while others had so little activity that they had been infiltrated by spammers promoting weight loss products! Active FaceBook pages allowed and encouraged postings to the company 'wall', organized events (usually developer conferences), added news, pictures and video, and even competitions. Some firms had multiple FaceBook pages, representing different brands, locations or markets: there were nearly 40 official Intel sites on FaceBook, for example.

There was a similar picture on Twitter, where companies such as Oracle were actively using 40 or so separate, official Oracle feeds as well as other contributions based on the brand names of other Oracle group products. Twitter, with around 100 million registered accounts, was represented across all of the sample, although some firms had Twitter accounts registered but were not actively using them: STMicroelectronics, for example, had 3 separate accounts but just a handful of active 'followers' and very little activity. Hynix, similarly, had only one posting since registration, while Infineon had no postings at all. Typically Twitter was being used by companies to headline press-releases, new products, developer events, new appointments, new blogs and videos.

It is difficult to comment on LinkedIn activity as all companies in our sample had official pages on the site. But as we observed with FaceBook, this appeared to be a function of the software. Even the smallest, Hynix, showed 260 staff on LinkedIn, compared to 81,000 for Oracle, 65,000 for Cisco and 48,000 members at Intel. Once again active social networkers were posting job vacancies and events. However, it was not clear exactly who was doing what, as activity is largely individual rather than corporate, and it was outside the scope of this exploratory study to 
examine how, for example, company staff were involved in industry and sector groups, in Q\&A sessions, etc.

When it came to photo sharing, again the findings were counter-intuitive. Although most of the companies in our sample were represented on Flickr, usually this was indirectly with pictures of company products or social events posted unofficially by third parties. Intel, Cisco and Oracle, however, all had official presences and were heavy users. Often these were publicity shots linked to news stories (Flickr therefore became a picture library for media organizations). They were widely viewed, also, with many examples having had thousands of page impressions and seemed to be an integral part of the social media branding programs of the companies involved.

Results for video-sharing were similar. Here, though, smaller companies were better represented: Renesas, for example, was showcasing nearly 80 videos while Qualcomm had uploaded nearly 170. Viewing figures for these were invariably small by B2C standards, being mostly in single figures with some examples showing 1000 or more 'hits'. Probably the biggest user of YouTube, though, was Oracle with over 250 uploads to YouTube, complementing a similar number available directly through its own web pages. Hynix and Infineon did not appear to use video promotion at all, either directly or using the YouTube platform.

Slideshare is another social media tool, but one used much more widely by B2B organizations than consumer marketers. It is a place where individuals and organizations can post and share slide shows such as exhibition and press conference presentations. While a number of our sample posted material of this kind on their own websites, several others used Slideshare also, notably Oracle and Cisco.

Podcasts (audio-only online broadcasts) are also often included in a general consideration of social media although they tend to be a one-way process without allowing for the possibility of audience commentary. One of the most extensive users was Cisco where a comprehensive archive of this material was available from the main web pages. Other companies were more circumspect: Qualcomm, for example, used the medium heavily to supplement product data pages, although there seemed to be no central repository. Still more firms adapted the medium: Intel, for example, 'broadcast' an entire channel entitled Future Labs Radio. Others such as Hynix, Renesas and STMicroelectronics, appeared not to use podcasts at all.

When it came to blogs, a similar pattern emerged. At one extreme companies such as STMicroelectronics and Hynix appeared only in other people's blogs while Oracle seemed heavily committed to the medium, often posting 400 blogs or more in a single month. Symantec was also active but like Oracle required users to register their details before being given access to the corporate blog. Cisco seemed a little less active: nevertheless their blogs were widely read, often with as many as 5000 viewings. Intel had its own blog pages, and in addition what they 
called The Intel Free Press. Generally, though, we found technology blogs from our sample hosted on corporate servers rather than in a Web 2.0 environment such as Google's Blogger or WordPress.

A similar picture emerged with so-called 'white papers', where experts comment on aspects of technology or business solutions. These pieces were often grounded on research and invariably were future-focused. Only Hynix and STMicroelectronics were missing from this process, although some company pieces (for example Renesas) were only discovered by means of a Google search. Most firms made white papers available in varying degrees: invariably, though, these required registration before being allowing access, which made quantification difficult.

Finally we looked at social bookmarks, Web 2.0 tools to make the archiving of information more efficient for time-pressed audiences. Almost all companies used RSS feeds, a comparatively crude system which notifies subscribers when the content of particular pages changes. But on the whole there was a similar haves and have-notch divide that we noted when looking at other platforms. Oracle, Cisco and Intel, for example, seemed to have made conscious decisions to encourage readers to bookmark their pages wherever possible: the key tools were Delicious, Diggit, Stumbledupon and Buzz.

\section{FINDINGS: TYPOLOGICAL}

At first sight, in our sample at least, there appeared to be a direct correlation between engagement in social media and company size: the three outstanding firms in terms of the use of Web 2.0 tools (Cisco, Intel and Oracle) were also the three largest. This assessment was based on the simple comparative assessment of engagement outlined in the previous section. However here the comparison ended, as Symantec and Qualcomm, the next most fluent companies in our assessment were also the smallest. Indeed, the dichotomy seems geographical: the five most successful companies in terms of social media were all American, while the remaining five were European or Asian. This is no aberration: between them the non-American 'laggards' employed approaching 250,000 people. The two German-registered companies in the sample seemed to perform better than their Korean, Japanese or Swiss competitors.

So, what is happening here? Even among the leading B2B users of social media there seemed to be a division in tactics: Cisco and some of the smaller companies appeared to maintain tight control over the social media outputs from their organizations, ensuring clarity, coherence and relevance. By contrast, the contributions from Intel and Oracle seemed random and chaotic: these companies appeared to be allowing technical and creative staff the license to speak to technology professionals without a pre-agreed script. 


\section{DISCUSSION}

In the light of this apparent confusion, perhaps it would be useful at this time to return to our four research questions. It may be that the literature, despite its limitations, will help up to explain an apparent east-west division in social media.

Our first research question wondered what part social media had to play in the development of an information-based approach to business-to-business branding. The content analysis in this study showed a wide disparity between the amount of information put out in the social domain by companies such as Oracle and Cisco, and the apparent laggards in our sample. The latter appeared to be relying on traditional sales-based approaches, supplemented by participation in trade fairs and developer events. The social media leaders, by contrast, not only filled the space with blogs, white papers, videos, podcasts and similar material, but by judiciously tagging these offerings and cross-referencing them on platforms such as Twitter and FaceBook ensured that each piece of knowledge received the maximum amount of visibility on search engines, each item multiplying its presence across the range of social media. Moreover, content-rich offerings such as slideshows and white papers were being linked within discussion groups and Q\&A sessions on LinkedIn and FaceBook, further continuing 'the conversation' and multiplying the impact through search engine optimization (SEO).

Our second research question wondered about the extent to which social media were able to play a part in actively managing business-to-business buyer-seller relationships. This is something which was more difficult to evaluate using the virtual ethnographic approach adopted. However, it was evident that the larger US companies had been able to build substantial virtual communities on FaceBook, and had some substantial audiences for their content-rich materials on YouTube, Slideshare and elsewhere. It appeared that companies such as Intel and Oracle actively encouraged staff to engage in conversations without undue corporate interference or control.

On a related theme, our third question wondered if social media could be used to facilitate the development of trusting relationships between buyers and sellers. Once again, it is less easy to assess emotional variables such as trust by looking in from the outside, but what seems clear is that in business-to-business sectors the audience for social media conversations is invariably small, with many of the parties involved known personally to each other. Discussions on FaceBook, comments on Twitter and answers on LinkedIn are not from random strangers as happens in consumer markets: to a large extent these interventions are virtual word-of-mouth, they are endorsements from trusted sources. This is particularly important where a company is adopting a vertical market strategy (such as SAP in this study). Such social media conversations not only invite deeper participation, but also reduce perceived risk where buyers and sellers are at an early stage of their business relationship. 
Finally, our last question wondered if social media could be used as a significant component of a market driving brand strategy in high-technology business-to-business markets. It appeared that this was being achieved by building knowledge leadership through a sustained application of social media, particularly the use of content-rich materials such as white papers, blogs and podcasts. In the case of firms such as Oracle, the process was as extensive as it was sustained: they seemed to exploit every opportunity to provide the marketplace with detailed evidence of their clear leadership in ideas, vision and strategy. It appears that the more innovative users of B2B social media are striving to position themselves as experts and seeking to influence the direction in which markets evolve by providing content-rich social media material (white papers, blog postings, and so on). Social media are emerging as a component of a market driving strategy.

\begin{abstract}
ANALYSIS
The fact that this study was focused around four indicative research questions suggests perhaps some contradictions of the more usual, inductive approach adopted by exploratory research. We would argue, though, that as it was clear that more than an adequate amount was known about both business-to-business branding and the particular differences of marketing in the technology sector, that this semi-hypothetical stance appeared justified. The open-ended and non-directed nature of the data collection process, moreover, allowed for additional reflections on the data to emerge. While we have already noted that technology companies in our sample appeared to be using social media tools in the ways suggested by published literature, we noted more than just a division between companies who did and those who did not engage with social media, those that embraced the new and those clinging to the old ways of branding: this was the aspect of control.

It seemed clear that the non-engaged companies such as Hynix and STMicroelectronics retained a 20th century approach to information and control: these companies gave away very little about themselves and appeared to be driven by traditional B2B structures based on exhibitions and personal selling; in other words marketing aimed to achieve careful information control. Firms such as Oracle and Intel, by contrast, appeared to empower staff to engage with wider audiences with little overt corporate oversight, as part of the process of developing 'thought leadership' in the sector. In these cases the companies' social media offerings could often look fragmented, chaotic and unplanned. Indeed some of the smaller companies such as SAP seemed to share the same randomness, bringing to mind the nature of the worldwide web at its inception in the 1990s when technical staff in all types of organization had more-or-less free rein to publish how they liked online. By the end of that decade, though, it seemed that marketing departments had been able to re-establish corporate control over outgoing communication, co-opting the web as another channel of outgoing communication. This protectiveness over the brand appears to continue to hold with the companies in our sample that we termed laggards in respect of social
\end{abstract}


media. However, there seems to be some evidence of the same strict branding control in the social media strategy of firms like Cisco Systems, where the not inconsiderable offerings seem ordered, highly structured and carefully controlled to deliver a consistent brand message.

It may be, of course, that Oracle's offering looks fragmented as a direct consequence of the speed at which the company has acquired businesses over the past decade and then integrated them within the Oracle brand: in time, therefore, a greater degree of uniformity might be exercised. Countering this, though, is the fact that the same apparently open information regime appears to apply at Intel, which has been comparatively stable in terms of corporate acquisitions. It may also be the case that the so-called laggards have the strategic will to develop the brands in the ways used by their US counterparts, but lack the linguistic skills to make this happen in an online sphere dominated by the English language.

It is also worth noting that these apparently laggardly firms appear to be extremely successful, between them employing close to a quarter of a million people: the question must be asked within these companies as to why they need to change to a branding strategy which would invariably play to the brand strengths of their US rivals. Moreover, while above-the-line costs for social media are comparatively small, the investment in staff time can be considerable, with consequent returns on this investment appearing to be trivial, given the low visibility and small impact that many blogs, videos and white papers appear to have.

This, perhaps, is to fail to understand the medium and its audience. While our research questions looked exclusively at business objectives and buyer-seller relationships, it is likely that much of what goes out in social media is addressing other stakeholder groups. Chief among these are likely to be investors, for whom the sheer online visibility of brands such as Oracle, Intel and Cisco provides assurances about their sustainable futures. Social media, particularly blogs and microblogs like Twitter, are a valuable way of building and maintaining relationships with traditional broadcast and print media, as well as the newer independent 'blogosphere': we noted how 'engaged' technology companies provided this constituency with easy-to-follow explanations, backed up with resources in terms of online photo libraries and research based white papers. It is likely, also, that a third audience for social media outputs is staff, both existing employees and prospective recruits; in the knowledge economy, where a company lives or dies by the creativity of its people, the internal marketing role of social media communication cannot be over-stressed.

\section{CONCLUSION}

We conclude that, at the time of writing (early 2012), there is extensive practitioner interest in the use of social media for B2B marketing. The primary social media considered to be useful for B2B marketing are LinkedIn, FaceBook, Twitter and blogging. The principal marketing 
applications of B2B social media are content marketing, market research, business networking and, possibly, sales prospecting. Social media are considered to be a vehicle for soft marketing through relationship and brand development, rather than a hard-sell vehicle.

Technology companies have used social media tools successfully to position their brands as thought leaders in a highly dynamic sector. For a range of important stakeholder groups companies such as Cisco, Oracle and Intel aim to show that they are market-driving: not only are they providing the hardware, connectivity and software to power the social media revolution, but these companies are embracing the mass collaboration business models that are gaining ground in business-to-consumer. Recent industry commentary has countered social media skeptics in the technology sector by pointing to ways in which B2B companies can usefully exploit platforms such as FaceBook and YouTube: our study shows that some of the leading companies are doing just that.

An important finding in our study was that there was so much variation in the levels of social media engagement among the 10 of the largest companies in the sector, with US firms appearing to lead the way. It would be useful to repeat the study with small and medium sized technology companies to see if the same patterns hold. It would also be useful to see the extent to which in a wider sample there were differences in engagement between product manufacturing companies and those providing software and systems: intuitively one would expect to find a difference, although this did not show itself in our study.

Similarly, it would be helpful to examine the take up of social media in business-to-business in the context of the overall adoption of these channels in different global markets: does a high consumer take-up of social media in one country translate into a correspondingly high usage in business-to-business markets? Finally, this would perhaps lead research into the more difficult area of return-on-investment in social media: how are the resources justified in B2B when the audience might number in hundreds, compared to figures of 100 times greater for consumer brands in social media?

\section{REFERENCES}

Constantinides, E. and Fountain, S.J. (2008). Web 2.0: Conceptual Foundations and Marketing Issues. Journal of Direct, Data and Digital Marketing Practice, 9 (231-244).

De Ruyter, K., Moorman, L. and Lemmink, J. (2001). Antecedents of Commitment and Trust in Customer-Supplier Relationships in High Technology Markets. Industrial Marketing Management, 30: (271-286).

Hills, S.B. and Sarin, S. (2003). From Market Driven to Market Driving: An Alternative Paradigm for Marketing in High Technology Industries. Journal of Marketing Theory and Practice, 11(3): 13-24. 
Hine, C. (2000), Virtual Ethnography, London: Sage Publications.

Kohli, A.K. and Jaworski, B.J. (1990). Market Orientation: The Construct, Research Propositions and Managerial Implications. Journal of Marketing, 54 (April): 1-18.

Leek, S., Turnbull, P. and Naude, P. (2003). How is Information Technology Affecting Business Relationships? Results from a UK Survey. Industrial Marketing Management, 32(2): 119-126.

Miller, D. and Slater, D. (2000), The Internet: An Ethnographic Approach, Oxford: Berg. Mohr, J.J. and Sarin, S. (2008). Drucker's Insights on Market Orientation and Innovation: Implications for Emerging Areas in High-Technology Marketing. Journal of the Academy of Marketing Science, 37(1):85-96.

National Text Mining Centre (2008). Text Mining: What Text Mining Can Do. Available from http://www.jisc.ac.uk/publications/briefingpapers/2008/bptextminingv2.aspx, accessed 10th December 2010.

Naude, P. and Holland, C.P. (2004). The Metamorphosis of Marketing into an Informationhandling Problem. Journal of Business \& Industrial Marketing, 19(3): 167-177.

Piercy, N.F. (2010). Evolution of strategic sales organizations in business-to-business marketing. Journal of Business \& Industrial Marketing, 25(5): 349 - 359.

Ryssel, R., Ritter, T. and Gemunden, H-G. (2004). The Impact of Information Technology Deployment on Trust, Commitment and Value Creation in Business Relationships. Journal of Business \& Industrial Marketing, 19(3): 197-207.

Sarin, S. and Mohr, J.J. (2008). An Introduction to the Special Issue on Marketing HighTechnology Products, Services and Innovations. Industrial Marketing Management, 37(6): 626-628.

Tapscott, D. and Williams, D. (2006), Wikinomics: How Mass Collaboration Changes Everything, London: Atlantic Books.

Weber, L. (2007), Marketing to the Social Web: How Digital Customer Communities Build Your Business, Hoboken, NJ: John Wiley \& Sons Inc.

Wilson, D. and Vlosky, R. (1998). Interorganizational Information System Technology and Buyer-Seller Relationships. Journal of Business \& Industrial Marketing, 13(3): 215234. 